\title{
Asphalt Rideability Specification and Construction of Expressways in Qatar
}

\author{
Roger James Hodgson \\ rhodgson@ashghal.gov.qa \\ Public Works Authority, Highway Projects Department, Doha, Qatar \\ Ali Kara \\ akara@ashghal.gov.qa \\ Public Works Authority, Highway Projects Department, Doha, Qatar
}

\begin{abstract}
Development of an Expressway network with a smooth ride quality is part of the Qatar 2030 Vision. The Public Works Authority (Ashghal) has placed high importance on the asphalt specification and quality of construction of the Expressway network to produce a perceived smooth, uninterrupted ride quality for the benefit of the traveling public. Ashghal has used a robust international specification for the International Roughness Index (IRI) and has required the Contractors and Supervision Consultants on the Expressway projects to produce an exceptional ride quality by training asphalt paving crews, using state-of the art asphalt paving and levelling equipment and quality control testing of the finished pavement. Various obstacles have been encountered in the Ashghal quest to produce world-class asphalt pavements and those obstacles have been overcome. This paper highlights the lessons learned from asphalt construction and aims to deliver to a wider audience the benefits of the Ashghal experience.
\end{abstract}

Keywords: International roughness index (IRI); Roughness; Pavement; Asphalt; Quality control

1 INTRODUCTION

The Qatar National Vision 2030:

"The National Vision aims at transforming Qatar into an advanced country by 2030, capable of sustaining its own development and providing for a high standard of living for all of its people for generations to come."

In order to achieve the above vision Qatar must balance five major challenges:

- Modernization and preservation of traditions.

- The needs of the present and future generations.

- Managed growth and uncontrolled expansion.

- The size and the quality of the expatriate labor force and the selected path of development.

- Economic growth, social development and environmental management.

To balance the above Qatar's national Vision Rests on the following four pillars:

- Human Development - Development of all its people to enable them to sustain a 
prosperous society.

- Social Development - Development of a just and caring society based on high moral standards, and capable of playing a significant role in the global partnership for development.

- Economic Development - Development of a competitive and diversified economy capable of meeting the needs of, and securing a high standard of living for, all its people for the present and for the future.

- Environmental Development - Management of the environment such that there is harmony between economic growth, social development and environmental protection.

Therefore, a world-class infrastructural backbone is essential to attaining the vision of economic development. This consists of a comprehensive urban development plan for Qatar that adopts a sustainable policy with regard to urban expansion and population distribution. In establishing a world leading specification for the roughness of the completed asphalt road pavements that have been constructed under the economic development pillar, Qatar has bridged both the Economic and Environmental pillars. Smoother roads lead to reduced fuel consumption, reduced driver fatigue, reduced vehicle wear and tear and reduced induced harmonic compression of the pavement. This resultant virtuous circle of benefits works towards the Environmental Pillar of the Vision.

\section{SPECIFICATIONS USED}

Qatar's Expressway Programme under the Public Works Authority, is one of World's largest road infrastructure projects currently under construction. It will deliver a worldclass new and upgraded road network in line with Qatar National Vision and cater to the 2022 FIFA World Cup. All projects across the Expressway Programme are required to report International Roughness Index (IRI).

IRI is defined as:

- A roughness parameter determined from a measured road profile in both wheel tracks.

- The measured profile is processed using a mathematical transform, which filters and cumulates the wavelengths encountered in the profile.

- Internationally recognized method of reporting detectable surface irregularity relating to the physical responses of vehicles on road surfaces.

- Pavement roughness, defined as an expression of irregularities in the pavement surface that adversely affect the ride quality of a vehicle (and thus the user). Roughness is an important pavement characteristic because it affects not only ride quality but also vehicle operating costs, fuel consumption (Fuel consumption ${ }^{2}=$ IRI) and maintenance costs.

- Roughness is also referred to as "smoothness" although both terms refer to the same pavement qualities.

The majority of the Expressway projects that have been constructed to date in Qatar have used the Qatar Construction Specification (QCS) 2010. This Standard did not have a definitive value for IRI and therefore Interim Advice Notes (IAN's) were written to give guidance for the IRI limits to be used during construction for acceptance of the completed asphalt surface. 
A typical IAN that was used was IAN 19, titled as "Amendments to Sections 5 and 6 of QCS 2010". Sections 5 and 6 being those concerned with pavement construction, roadworks and asphalt works. IAN Specification for the IRI on new pavement construction is:

a) Flexible Pavement: Average value over a 400 meter section - $0.90 \mathrm{~m} / \mathrm{km}$

b) Composite and Rigid Pavement: Average value over a 400-meter section - $1.20 \mathrm{~m} /$ $\mathrm{km}$.

The IAN specifies that peak individual value over a 25 -meter section shall be 1.5 $\mathrm{m} / \mathrm{km}$ (Not more than 2 values per 400 meters) for New construction, Reconstruction and Pavement rehabilitation. It came to Ashghal's attention that projects are being affected by inconsistencies in the type and manufacturer of IRI equipment being used and inconsistent Project Specifications where the Supervision Consultants' (SC's) were not fully aware of test requirements.

This includes specifics where SC's were not aware of reported variance requirements in order to confirm accuracy of results being reported or the method of reporting the results. IRI testing has to be reproducible providing a consistent measurement. It was discovered that not all projects analyze and report IRI test results in the same format. Some projects also had different specification requirements. It is important that all profilers are correctly calibrated and consistent testing procedures are adopted on all projects.

\section{SPECIFICATION PROBLEMS}

Ashghal understands that the Programme Management Consultants (PMC) developed this specification and a very similar specification has been used in the Kingdom of Saudi Arabia (KSA) for some time. It is worth noting here that the $400 \mathrm{~m}$ treatment length is unusual with respect to other international specifications. It is thought that the $400 \mathrm{~m}$ treatment length was used in order to assess longer wavelength rideability criteria. Therefore, the 400m length may not be suitable for Qatar Expressways.

Also there was debate if the $400 \mathrm{~m}$ section should be reported as $400 \mathrm{~m}$ rolling average (i.e. drop one $25 \mathrm{~m}$ average section and add one $25 \mathrm{~m}$ section) or $400 \mathrm{~m}$ discrete blocks. Analysis of the ASTM standard E1926-08R15 - Computing International Roughness Index, indicates that the averaging of the results should be reported over $25 \mathrm{~m}$ only. Therefore reporting a rolling average of the $400 \mathrm{~m}$ sections would result in a doubling of the smoothing, leading to non-representative results and difficulty in pinpointing isolated areas of roughness.

On analysis of the manufacturers internal reporting software on the class 1 laser profilers used, it was apparent that the averaging of individual IRI results has indeed been carried out over $25 \mathrm{~m}$ sections.

\section{INSTILLING THE NEED AND LESSONS LEARNED}

It became apparent to Ashghal during construction of the multi-layer asphalt pavements that the level of awareness regarding the importance of meeting the stringent IRI specification and providing a world-class smooth pavement was inconsistent in the 
Contractors, Supervision Consultants and the third party testing laboratories. Ashghal therefore, initiated on-site training programmes stressing the importance of meeting the IRI specification and what was expected of the Contractors and Consultants. The outcome was that many of the contractors started to carry out IRI testing on the intermediate asphalt course prior to laying the final asphalt-wearing course. In this way, there was capacity to carry out any repairs or rectification to the underlying layer prior to laying the wearing course.

Asphalt wearing courses were laid using a minimum 9m, but preferably 11 to $13 \mathrm{~m}$ ultrasonic averaging beams, commonly referred to a "multiplex" levelling system. All third party testing laboratories that carry out IRI were invited to a workshop hosted and arranged by Ashghal to ensure consistency in testing methodology and reporting format.

\section{CONCLUSION AND RECOMMENDATIONS}

From Ashghal's experience in producing and meeting an IRI Specification, a number

of conclusions have been made, they are:

- That there is a need to establish a reference profile against which all the profilographs used for IRI measurement in Qatar can be referenced against. This can set the precision and bias of the profilographs.

- The Specification for IRI should reflect what the owner is expecting to achieve. Using a $400 \mathrm{~m}$ section for reporting is too long for Qatar, a more realistic section would be $150 \mathrm{~m}$, this in-keeping with relevant international standards (Múčka, 2017).

- Rideability can be improved by effective paving plans and by executing the wearing course in long stretches to minimize the number of cold transverse joints.

- Contractors should be made aware of the need to produce smooth pavements at the start of construction and significant financial incentives provided to produce a better than specified IRI.

- Every effort should be made at the design stage to remove ironworks such as handhole covers, personnel access covers for chambers and openings in the carriageway to ensure a smooth running surface.

\section{REFERENCES}

American Association of State Highway and Transportation Officials (AASHTO), Geometric Design of Highways and Streets, $7^{\text {th }}$ Edition.

Ashghal Interim Advice Note No. 19, revisions 2 \& 3, Amendments to Sections 5 and 6 of QCS 2010, Public Works Authority, Ashghal.

ASTM Standard E1926-08R15 - Standard Practice for Computing International Roughness Index of Roads from Longitudinal Profile Measurements.

Múčka, Peter (2017) International roughness index specifications around the world. Road Materials and Pavement Design, 18:4, 929-965.

Qatar Construction Specification (QCS) 2010. 